\title{
Typhlitis: A Rare Appendicitis Mimic in a Young Healthy Female
}

\author{
Jonathan Vincent M. Reyes ${ }^{1}$, Salman B. Syed ${ }^{2}$, Tasur Seen $^{1}$, Nirali Sheth ${ }^{1}$, Christopher Kowalczyk ${ }^{1}$ \\ 1. Internal Medicine, Icahn School of Medicine at Mount Sinai, Elmhurst Hospital Center, Elmhurst, USA 2. Internal \\ Medicine, University of Illinois College of Medicine, Peoria, USA
}

Corresponding author: Salman B. Syed, salman.syed@osfhealthcare.org

\begin{abstract}
Typhlitis, also known as neutropenic enterocolitis, is a rare but serious condition characterized by inflammation of the cecum causing right lower quadrant (RLQ) pain and fever. It typically affects immunocompromised patients with neutropenia, hematologic malignancies, AIDS, or those on immunosuppressive therapy. This is an entity that should be considered in any differential for a patient with febrile RLQ pain, not just those with obvious immunosuppression.
\end{abstract}

Categories: Internal Medicine, Radiology, Gastroenterology

Keywords: typhilitis, neutropenic colitis, enterocolitis, c. diff colitis, appendicitis, right lower quadrant pain, rlq pain

\section{Introduction}

Typhlitis, a severe inflammatory state of the cecum is a rare condition affecting mainly neutropenic and immunosuppressed patients. It typically affects immunocompromised patients with neutropenia, hematologic malignancies, AIDS, or those on immunosuppressive therapy [1]. It frequently mimics appendicitis on presentation with a triad of abdominal pain, fever, and neutropenia, and it is diagnosed using computed tomography (CT) imaging. However, given the extent of morbidity and mortality, early diagnosis for immunocompromised patients is imperative. There is limited literature on the incidence and pathogenesis of typhlitis as well as few reported cases on non-immunocompromised patients [2].

\section{Case Presentation}

A 25-year-old female, reporting no past medical history, presents to the emergency department with a oneweek history of recurrent right lower quadrant (RLQ) abdominal pain. She describes three episodes of nonbloody diarrhea in the morning. She denies fevers, nausea, vomiting, or prandial/postprandial pain. She has no personal or family history of cancer or autoimmune diseases.

Review began 05/31/2021 Review ended 06/08/2021 Published 06/22/2021

๑) Copyright 2021

Reyes et al. This is an open access article distributed under the terms of the Creative Commons Attribution License CC-BY 4.0., which permits unrestricted use, distribution, and reproduction in any medium, provided the original author and source are credited.
On physical exam, vitals are significant for fever to $100.9^{\circ} \mathrm{F}$. The abdomen is soft, mildly distended, moderately tender to palpation in the RLQ, and without rebound tenderness. Initial lab work was remarkable for microcytic anemia with hemoglobin ( $\mathrm{Hgb}$ ) to 10, mean corpuscular volume (MCV) 76, leukocytosis to 12.32, absolute neutrophil count $1196\left(2.10-7.60 \times 10^{3}\right.$ cells $\left./ \mu \mathrm{L}\right)$, lactate 1.1 , and HIV-negative. The clinical picture was concerning for appendicitis. CT abdomen and pelvis demonstrated inflammatory thickening of the cecum (Figures 1,2). The patient was admitted to general surgery for conservative management with bowel rest, intravenous (IV) Zosyn, and pain management. The patient improved and was discharged home on oral antibiotics. During her primary care follow-up visit, the patient endorsed the resolution of her symptoms. 


\section{Cureus}

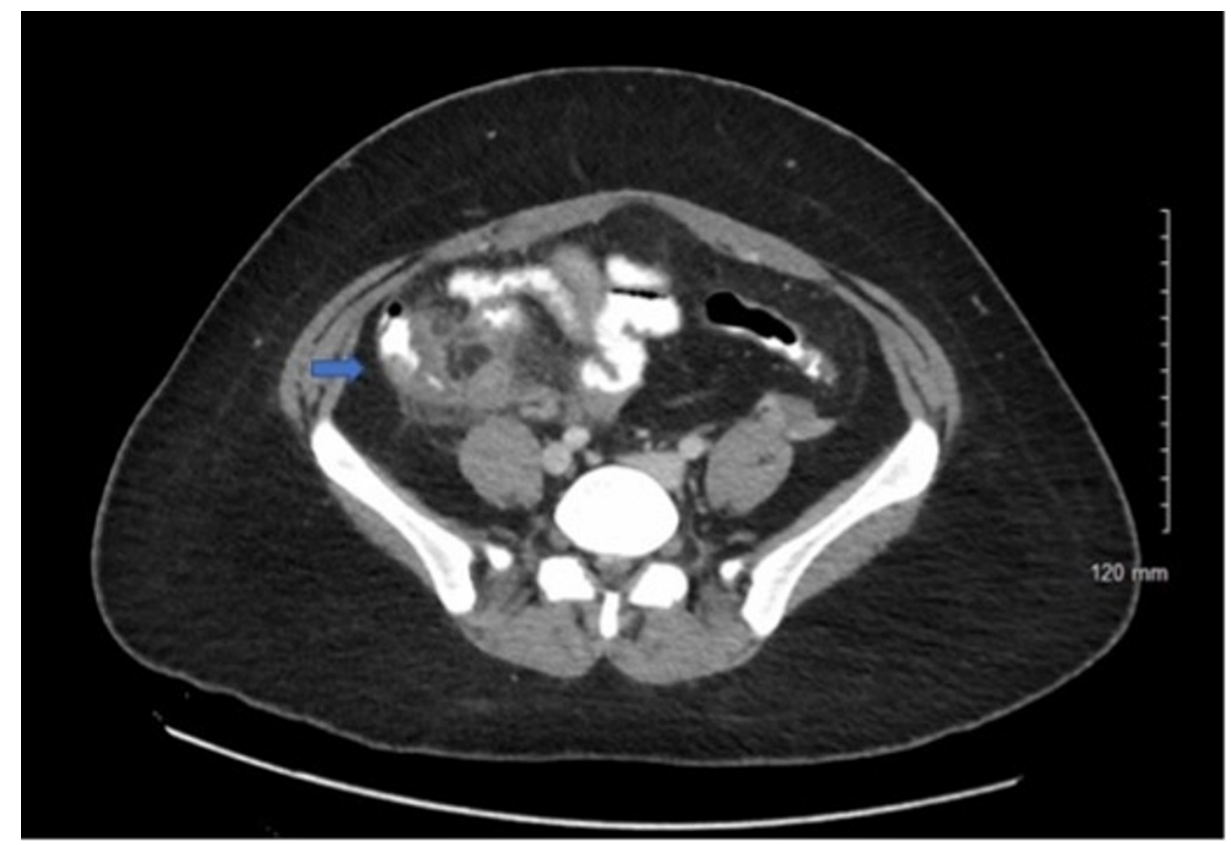

FIGURE 1: CTAP with contrast: transverse view demonstrating inflammatory thickening of cecum

CTAP, Computed tomography arterial portography. 


\section{Cureus}

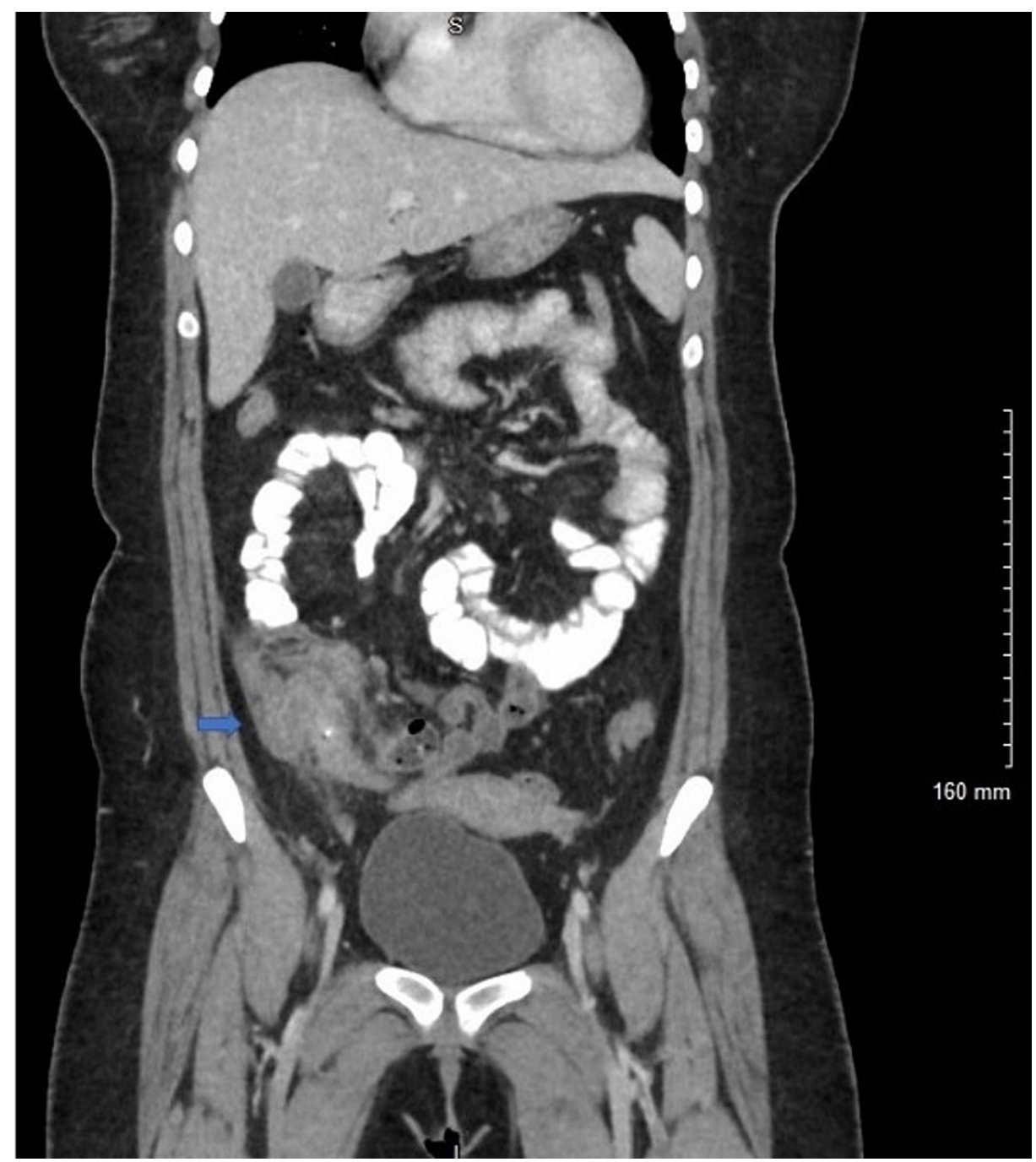

\section{FIGURE 2: CTAP with contrast: coronal view demonstrating}

inflammatory thickening of cecum

CTAP, Computed tomography arterial portography.

\section{Discussion}

Neutropenic enterocolitis, more commonly referred to as typhlitis, is a severe inflammatory disorder of the intestines that generally occurs in neutropenic and immunosuppressed patients. Given the described population, it may not be surprising that morbidity in this pathology is estimated between $21 \%$ and $48 \%$ [3].

Conventionally, it is thought that patients cannot have typhlitis without lab-confirmed immunosuppression [4]. However, the diagnosis is confirmed with radiologic evidence. While the pathogenesis is not well understood, it is thought that neutropenia and states of immunosuppression may lead to intestinal edema and disrupted mucosal surface. This disruption allows for the translocation of bacteria. Treatment consists of IV antibiotics and bowel rest. Surgery is considered for complications related to necrosis $[5,6]$.

Our patient had a typical presentation and compatible CT findings; notably, identification of cecitis despite leukocytosis led to conservative versus operative management as well as diagnosis of typhlitis. Ultrasound is typically the first radiologic evaluation for this presentation as it is a faster modality with high sensitivity for appendicitis and typhlitis [7], but considering further characterization of bowel inflammation on CT has been recommended when it does not significantly delay diagnosis. Bowel wall thickening and inflammation of the cecum detected by CT have been proposed as the main criterion to establish the diagnosis of typhlitis $[2,4,5,7-9]$. The extent of bowel wall thickening is also a valuable prognostic factor, which adversely affects the outcome [9]. In addition to these findings, appendiceal dilatation on CT is typically observed with appendicitis, which was not visualized in our patient. 
colitis is another severe disease on the differential in this patient population. Between these three pathologies (appendicitis, typhlitis, $C$. diff colitis), there is a great overlap in the symptomatology and patient history, so radiologic variables become increasingly important for narrowing the diagnosis. Given that some degree of bowel necrosis is common in typhlitis, pneumatosis intestinalis on CT imaging is most associated with typhlitis. Comparably, bowel wall thickening is non-specific and can be found in all three disease states, but wall nodularity is highly specific for $C$. diff colitis [8].

\section{Conclusions}

In conclusion, this case is to inform clinicians of a rare appendicitis mimic. This case aims to broaden the possible differential diagnosis for patients who present with nausea, vomiting, fever, and RLQ pain. Imaging will assist with an early diagnosis, which will in turn limit complications and potentially reduce morbidity. Further research is warranted to see how early diagnosis affects patient outcomes.

\section{Additional Information \\ Disclosures}

Human subjects: Consent was obtained or waived by all participants in this study. Conflicts of interest: In compliance with the ICMJE uniform disclosure form, all authors declare the following: Payment/services info: All authors have declared that no financial support was received from any organization for the submitted work. Financial relationships: All authors have declared that they have no financial relationships at present or within the previous three years with any organizations that might have an interest in the submitted work. Other relationships: All authors have declared that there are no other relationships or activities that could appear to have influenced the submitted work.

\section{References}

1. Abu-Hilal MA, Jones JM: Typhlitis; is it just in immunocompromised patients?. Med Sci Monit. 2008, 14:CS67-70.

2. Debnath J, Sharma V, Ravikumar R, et al.: Clinical mimics of acute appendicitis: is there any role of imaging?. Med J Armed Forces India. 2016, 72:285-92. 10.1016/j.mjafi.2015.01.017

3. Rodrigues FG, Dasilva G, Wexner SD: Neutropenic enterocolitis. World J Gastroenterol. 2017, 23:42-7. 10.3748/wjg.v23.i1.42

4. Kirkpatrick ID, Greenberg HM: Gastrointestinal complications in the neutropenic patient: characterization and differentiation with abdominal CT. Radiology. 2003, 226:668-74. 10.1148/radiol.2263011932

5. Demir MK, Savas Y, Furuncuoglu Y, Cevher T, Demiral S, Tabandeh B, Aslan M: Imaging findings of the unusual presentations, associations and clinical mimics of acute appendicitis. Eurasian J Med. 2017, 49:198203. 10.5152/eurasianjmed.2017.17218

6. Sloas MM, Flynn PM, Kaste SC, Patrick CC: Typhlitis in children with cancer: a 30-year experience . Clin Infect Dis. 1993, 17:484-90. 10.1093/clinids/17.3.484

7. Tamburrini S, Setola FR, Belfiore MP, et al.: Ultrasound diagnosis of typhlitis. J Ultrasound. 2019, 22:103-6. 10.1007/s40477-018-0333-2

8. Sargar KM, Siegel MJ: Sonography of acute appendicitis and its mimics in children . Indian J Radiol Imaging. 2014, 24:163-70. 10.4103/0971-3026.134404

9. Gorschlüter M, Mey U, Strehl J, et al.: Neutropenic enterocolitis in adults: systematic analysis of evidence quality. Eur J Haematol. 2005, 75:1-13. 10.1111/j.1600-0609.2005.00442.x 